\title{
Mid-Sequence Archaeology at the Sigatoka Sand Dunes with Interpretive Implications for Fijian and Oceanic Culture History
}

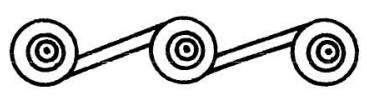

DAVID V. BURLEY

FEW OTHER SITES IN THE HISTORY of Oceanic archaeology have spawned as much research investment as the Sigatoka Sand Dunes on the Coral Coast of Viti Levu in Fiji (Figure 1). Continuous erosion on the face of this extraordinary geological feature over the past half-century has exposed a wide array of archaeological materials dating from the initial period of Fijian settlement up to and including the historic era. Numerous archaeologists have conducted surveys, surface collections, or excavations here, and each has used his or her results to create or refine our understanding of the site and Fijian prehistory. As was illustrated in pivotal excavations at the dunes in the mid 1960s by Lawrence Birks (1973), the ability to delineate cultural complexes at Sigatoka is greatly enhanced by large volumes of temporally diagnostic ceramics, including restorable vessels, by a rapid burial of archaeological remains and by consequential separation of cultural strata by sterile lenses of sand.

Yet, and in spite of the large number of projects, the Sigatoka Sand Dunes archaeological record remained enigmatic, if not problematic, at the turn to the twenty-first century (see Marshall et al. 2000). Notwithstanding the literally hundreds of thousands of ceramic sherds recovered from the site and the widespread occurrence of human burials (Best 1989; Visser 1994), only limited evidence for sustained occupation was present (Birks 1973; Burley 1997; Burley and Shortland 1999; Hudson 1994). Indeed, prior to 2000 architectural or habitation features were rarely encountered, faunal material of any substance was nonexistent, and the nonceramic artifact assemblage amounted to little more than the occasional adze or grinding stone (Birks 1973:47-50). And in a recent review of Sigatoka archaeology by Marshall et al. (2000:5-8), even the usefulness of the Sigatoka ceramic sequence for modeling Fijian culture history was challenged.

In this paper, I present initial results of an excavation project undertaken on the eastern end of the Sand Dunes in May and June of 2000. Recovered materials resolve many of the incongruities as given, and they provide a new and important data set by which to reconfigure an understanding of mid-sequence occupations

David V. Burley, Professor, Department of Archaeology, Simon Fraser University.

Asian Perspectives, Vol. 44, No. 2 (C) 2005 by the University of Hawai' ${ }^{i}$ Press. 


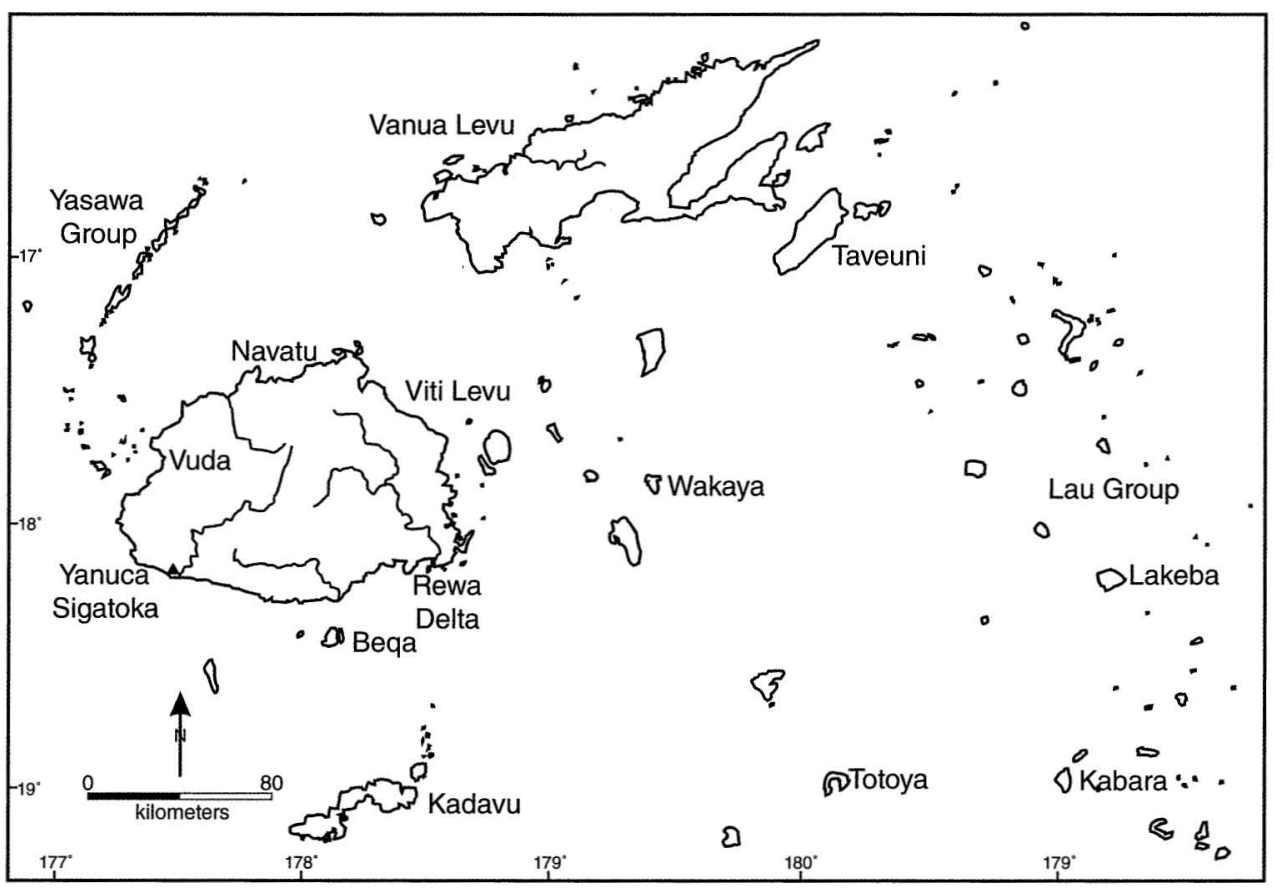

Fig. 1. Fijian Islands with place and site names mentioned in text.

at Sigatoka. The data come from stratigraphically separated habitation floors, each with architectural features, distinctive ceramic suites, nonceramic artifact assemblages, and faunal remains. Ceramics from the lower component correlate with what I will call the Fijian Plainware phase, with continuity in vessel form and technology extending back to the Lapita period in Fiji. The upper component relates to the Navatu phase, it having a different ceramic assemblage as defined by the presence of distinctive new vessel forms, a new range of decorative applications, and, possibly, a variant manufacturing technology. Plainware and Navatu occupation floors are very closely spaced in time at Sigatoka, and diagnostic ceramics for each are found elsewhere on the dune associated with what Birks (1973) defined as the "Level 2" paleosol. A reevaluation of this paleosol, and its associated cultural remains, serves to highlight earlier misunderstandings of the Sigatoka archaeological record with important implications for Fijian prehistory as a whole.

\section{GEOMORPHIC AND ARCHAEOLOGICAL CONTEXT OF THE SIGATOKA SAND DUNES}

Rising to elevations of up to $60 \mathrm{~m}$, the Sigatoka Sand Dunes are a visually impressive system of parabolic dunes extending along the coast from the mouth of the Sigatoka River west for a linear distance of $4.8 \mathrm{~km}$. The dunes are formed largely from iron sands eroded from inland slopes of the Sigatoka River valley (Dickinson 1968; Dickinson et al. 1998). Because of the river's freshwater flow 
combined with offshore currents running to the west, the Sigatoka coastline is without fringing reef. Sediments thus are carried downriver, pushed longshore, and eventually washed onto the beach by strong surf surge. Daily southeast winds blow the sand obliquely inland, creating elongate, southeast-to-northwestoriented dunes in the process. Much of the inland slope and surface of the dune field is now stable, covered in grasses and other forms of vegetation. The frontal face along the coast, however, remains active, with wave attack, high-velocity winds, and other disruptive processes, including human agency, leading to erosion and sediment redistribution. Through these processes archaeological and human remains are continuously exposed.

Archaeology has been critical to geological modeling and interpretations of dune origin and expansion. Geological contexts and features are given temporal reference by archaeological association, and archaeology provides a mechanism to track sand accumulation above and between occupation floors. Based on these data, Dickinson et al. (1998) and de Biran (2001) suggest the onslaught of sand accumulation at Sigatoka did not begin until approximately 500-600 C.E. In explanation, it is hypothesized that agricultural clearing and slope erosion along the mid and upper Sigatoka valley led to significantly increased sediment loads in the river at that time (after Parry 1987). Marshall et al. (2000:15) alternatively propose that at least the eastern end of the dune field had been formed by the time of first human arrival in Fiji (ca. 950 B.C.E.). A resolution of this debate, and the data upon which it is based, is beyond the scope of present discussion (see Burley and Dickinson 2004:15-16; Marshall et al. 2000:54-67). As is to be examined subsequently, however, a later origin for the dune is supported by archaeological data presented here, and it provides a context through which these data can be explained.

By the 1960s, the potential of Sigatoka for understanding Fijian culture history was suspected by archaeologists. Thus, when Green remolded Gifford's (1951) Fijian sequence into a four-period chronology in 1963, he included a Sigatoka phase. This phase was correlated with a distinctive suite of ceramic features and adze types found at Sigatoka and elsewhere in New Caledonia, Tonga, and Samoa. In Green's (1963:250-251) view, these represented the initial presence of "proto-Polynesian" peoples in Fiji. In 1965, Birks (1973) proved the site's archaeological potential through extensive excavations on the eastern end of the dune, recovering an abundance and range of pottery types, including many that could be reconstructed into complete or substantially complete vessels (also Burley and Dickinson 2004). With $2610.6 \mathrm{~m}^{2}$ of surface area excavated by 1966 , Birks's project continues to be the most expansive excavation ever undertaken in this part of the Pacific, and his detailed analyses of vessel forms and characteristics serve as a pivotal reference for ceramic studies across Oceania. It also was Birks (1973), in consultation with the geologist Dickinson (1968), who correlated human occupations at Sigatoka with periods of surface stability as evident by a series of stratigraphically separated paleosols. These were designated Levels 1, 2, and 3, with respective ceramic assemblages associated with Sigatoka (late Lapita), Navatu, and Vuda phases (see Marshall et al. 2000:6). Archaeologists have occasionally queried the number of paleosols, their integrity, and/or their complexity (Burley and Dickinson 2004; Hudson 1994; Marshall et al. 2000; Petchey 1995), but they 
continue to stand as a stratigraphic and temporal reference for archaeological remains at Sigatoka.

Since Birks's landmark excavations, numerous other projects have been carried out at Sigatoka, most in response to resource management issues and site degradation (Marshall et al. 2000:34-35). Cumulatively these projects allow us to draw several conclusions about the archaeological record as a whole. First, while there is scattered evidence for human presence over the entire length of the dune, the most intensive archaeological deposits are concentrated on the eastern end for an approximate distance of $1.5 \mathrm{~km}$ from the river mouth. Second, the archaeological remains at Sigatoka span the entire chronological sequence of Fiji, from the early Lapita settlement period up to the historic era. These remains include not only diagnostic ceramic assemblages, but human skeletal materials, including an elaborate cairn burial cemetery associated with Level 2 (Best 1989). Third, the archaeological record of Sigatoka is discretely episodic, having no less than six occupation periods represented. Fourth, because of the discrete nature of occupation, and the stratigraphic separation of cultural components by intervening layers of sand, the archaeological record is instrumental to an accurate delineation of the Fijian ceramic sequence. In this it facilitates an understanding of culture historical relationships on Viti Levu, if not the archipelago as a whole. And finally, human occupation or use of the Sigatoka beachfront was highly dynamic. It was structured by the interplay of people and place in response to changing geological and ecological circumstances as well as human motivations (Burley 2003; Burley and Dickinson 2004).

PLAINWARE/NAVATU SETTLEMENTS, THE 2000 EXCAVATION PROGRAM, AND RECOVERED DATA

The 2000 project was undertaken as one component of a field school offered by Simon Fraser University in coordination with the Fiji Museum and the National Trust for Fiji. The initial survey of the dune front discovered an exposure of ceramics, firebroken rock, fragmented shellfish remains, a possible hearth feature, and other materials on the surface of a low, blown-out swale on the extreme eastern end (Figures 2 and 3). This material was dispersed over an area approximately $17 \times 10 \mathrm{~m}$ in size with full exposure of the living surface broken by remnant patches of drift sand. The locale previously was reported as having Level 2 ceramics (Marshall et al. 2000:25), and a 1995 Fiji Museum excavation had taken place in the Level 3 paleosol immediately to the north and upslope (Burke 1995). Based on sherd types recovered from the surface, the exposed occupation floor was associated with the Navatu phase. Auger tests and test excavations illustrated a second occupation floor $25-30 \mathrm{~cm}$ below with a sand stratum intervening. Ceramics from the lower component were concordant with what Marshall et al. (2000:71) identify as "late Lapita Plainware pottery" on inland beach ridges behind the dune. To avoid confusion with the late Lapita ceramic assemblage from Level 1 (Burley and Dickinson 2004), and for other reasons to be explained subsequently, these ceramics and the period they represent were labeled Fijian Plainware. Ensuing excavation of the Navatu and Fijian Plainware occupation floors included a total area of $21.4 \mathrm{~m}^{2}$ (Figure 3). An additional $36 \mathrm{~m}^{2}$ of this deposit 


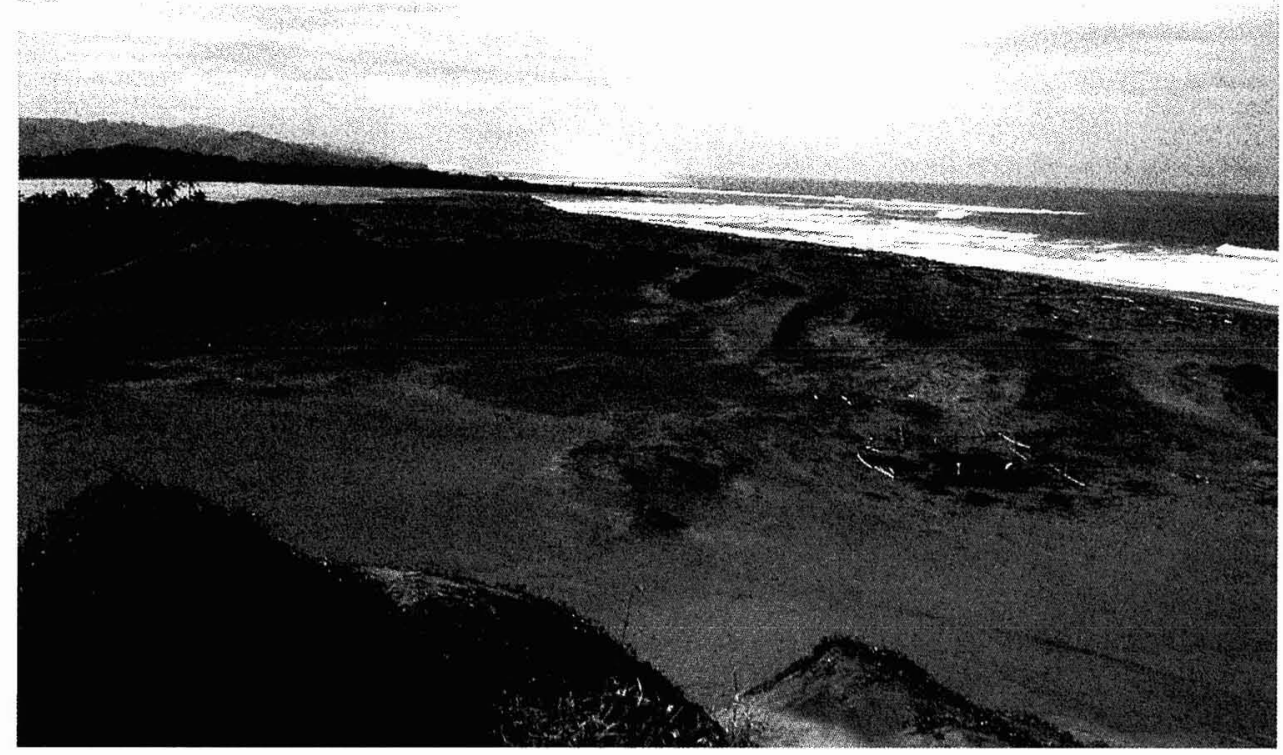

Fig. 2. Eastern end of the Sigatoka Sand Dunes, with mouth of the Sigatoka River in the background. The 2000 excavation block area is located in the lower right corner.

was excavated in 2002. Materials from that project are only now being analyzed, but they help to inform and structure interpretations in the present paper.

Excavation exposed four principal strata (Figure 4). The upper Navatu stratum is incorporated within dark brown sand. It extends from the surface to a maximum depth of $15 \mathrm{~cm}$, albeit its lower boundary is not well defined. Aside from ceramics, it includes whole and broken shellfish, bone, nonceramic artifacts, fire broken rock, a hearth, two earth oven features, and several postholes. This range of materials and features does not occur elsewhere on the dune front, and they clearly indicate a living floor on which habitation took place. Intervening between this and the lower cultural horizon is a $10-15 \mathrm{~cm}$ thick deposit of looser brown sand. Turbation and feature intrusion have scattered a mixed assemblage of ceramics, fauna, and other materials from upper and lower components throughout. The lower Fijian Plainware component is abruptly defined as a dense and compact floor of ceramics between 25 and $30 \mathrm{~cm}$ below the surface (Figure 4). Faunal remains continue to be present, which, with nonceramic artifacts and posthole features, similarly identify the deposit as a habitation floor. The lower Plainware component rests on a stratum of olive green (moist) to lighter brown (dry) sand. While thought initially to be culturally sterile, 2002 excavations into the stratum recovered a concentration of sherds from a single notched and expanded rim pot (late Lapita Level 1) as well as two pieces with dentate stamped Lapita decoration.

Seven charcoal samples from what are believed to be secure stratigraphic associations were submitted for AMS radiocarbon dating to the Lawrence Livermore National Laboratory in California (Appendix A). Three of these were taken from 


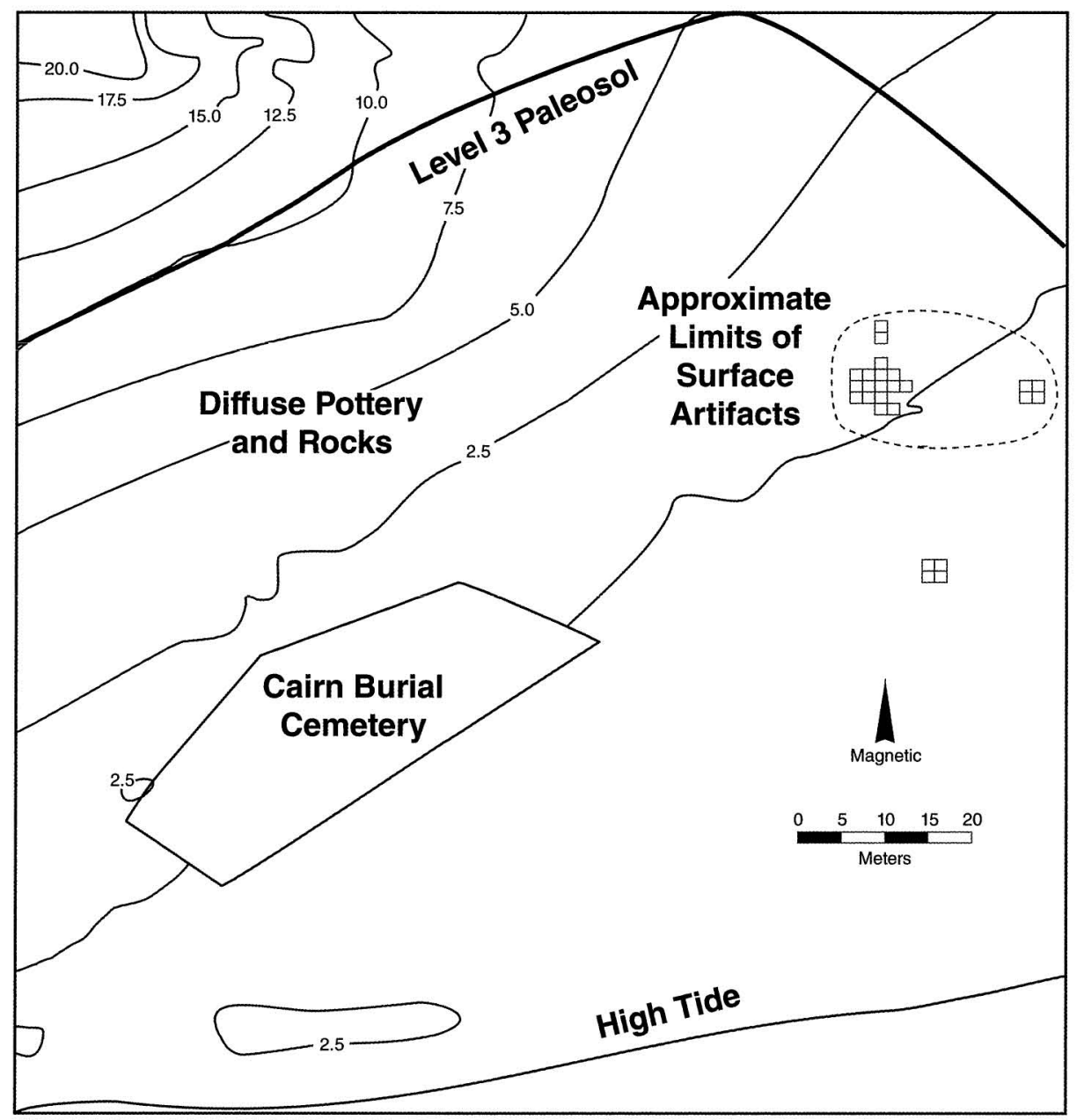

Fig. 3. Sigatoka Sand Dune 2000 excavation project, including location of cairn burial cemetery excavated by Best (1989). The outline of the cemetery is in reference to a fence that was placed around the area following Best's excavations.

Navatu Phase contexts while the remaining four were associated with the Plainware phase occupation. All samples were measured for $\delta^{13} \mathrm{C}$ and dates were corrected accordingly. In relative comparison to the rest, one of the Plainware samples (CAMS 68195) appeared far too recent in age. To eliminate the possibility of laboratory error, a second date (CAMS 70921) from the same sample was run, it similarly illustrating the sample to be an outlier. When calibrated to one $\sigma$ using Oxcal, a combined age for the three Plainware dates excluding the outlier provides a range of 435-535 C.E. Doing the same for the Navatu occupation places it between 604 and 646 C.E. When calibrated at a two $\sigma$ range and combined, the respective ranges are 420-550 C.E. and 560-660 C.E. Since these occupations are discrete events separated by a layer of sand, it can only be concluded that the last vestiges of the Plainware phase settlement is separated in time from the begin- 


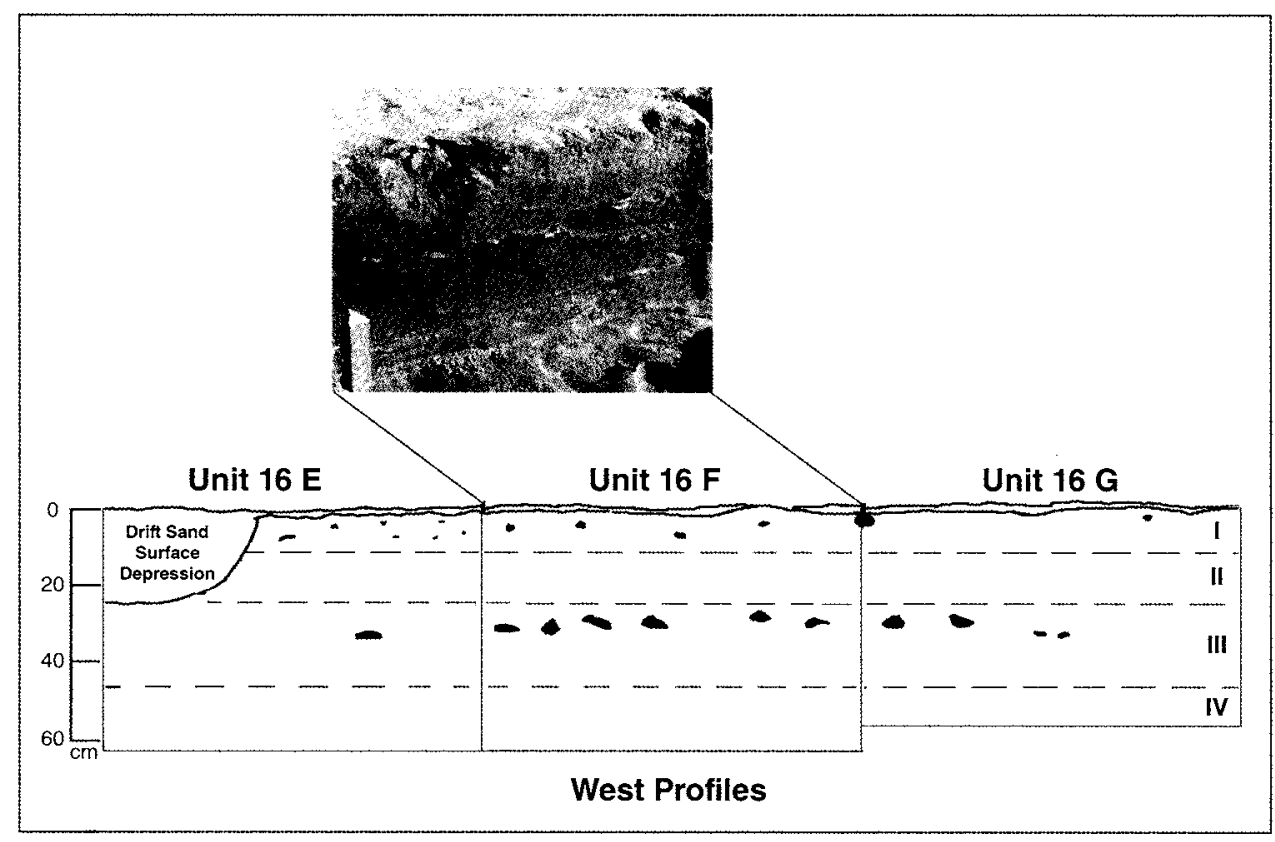

Fig. 4. Excavation profile and stratigraphy of Sigatoka Sand Dune excavation in 2000. The ceramic layer in Stratum III is the Fijian Plainware phase occupation floor. The Navatu phase occupation floor occurs on the surface and in the upper $10 \mathrm{~cm}$.

nings of the Navatu Phase occupation by no more than a century or two, and most probably less.

In total, 47,501 ceramic sherds were recovered from excavations in 2000. These are tabulated in Table 1 by sherd type, and associated with Navatu, Plainware, or a mixed component. The latter comes from excavation units in which two earth oven features had fully integrated Navatu and Plainware ceramics in pit fills and adjacent deposits. Vessel types or rim course profiles for bowls and jars are

Table i. Ceramic Sherd Types Recovered from Navatu and Fijian Plainware Phase Occupation Floors during the 2000 Excavation Project

\begin{tabular}{lrrrr}
\hline & NAVATU & PLAINWARE & MIXED & TOTAL \\
\hline Rim & 360 & 1,082 & 148 & 1,590 \\
Shoulder/neck & 792 & 2,619 & 58 & 3,469 \\
Body & 9515 & 31,928 & - & 42,379 \\
Handle/lug & - & 16 & - & 16 \\
Spout & - & 14 & - & 14 \\
Disk & - & 5 & - & 5 \\
Other & 6 & 22 & 1,142 & 47,501 \\
Total & 10,837 & 36,016 & \\
\hline
\end{tabular}

Note: The "other" category includes miscellaneous lumps of fired clay, wasters, and various unidentified ceramic pieces. 
Table 2. Vessel Form Identifications and Rim Course Profiles Recovered from Navatu and Fujian Plainware Phase Occupation Floors during the 2000 Excavation Project

\begin{tabular}{lrrrr}
\hline & NAVATU & PLAINWARE & MIXED & TOTAL \\
\hline Jars & & & & \\
Navatu everted-plain lip & 4 & 0 & 0 & 4 \\
Navatu everted-notched lip & 60 & 0 & 9 & 69 \\
Short necked jar & 35 & 133 & 7 & 175 \\
Everted-rounded neck & 27 & 63 & 7 & 97 \\
Slightly everted/straight & 62 & 178 & 15 & 255 \\
Inverted & 22 & 67 & 14 & 103 \\
S-shaped rim/neck & 0 & 4 & 2 & 6 \\
$\quad$ Total & 210 & 445 & 54 & 709 \\
Bowls & & & & \\
Cup (diameter $<15$ cm) & 2 & 9 & 0 & 11 \\
$\quad$ Everted-thickened rim & 3 & 25 & 3 & 33 \\
$\quad$ Everted direct & 42 & 25 & 13 & 125 \\
Straight & 5 & 113 & 0 & 33 \\
Inverted direct & 36 & 4 & 35 & 4 \\
Inverted with carination & 0 & & & 368 \\
$\quad$ Total & 88 & 5 & 0 & \\
Trays & & 0 & 1 & 5 \\
Flattened palette & 0 & 5 & 1 & 4 \\
Salt tray & 3 & & & 9 \\
$\quad$ Total & 3 & &
\end{tabular}

identified by component in Table 2 while rim, neck, or body sherds with decorative applications are similarly identified in Table 3. The limited size for most sherds, the use of generic rim course profiles for ceramic classification, and at least some probability of mixing from feature intrusion and turbation provides an

Table 3. Major Decorative Applications for Navatu and Fijian Plainware Phase OcCupation Floors during the 2000 Excavation Project

\begin{tabular}{|c|c|c|c|c|}
\hline & NAVATU & PLAINWARE & MIXED & TOTAL \\
\hline End tool impression & 10 & - & 2 & 12 \\
\hline Side tool impression & 24 & - & 3 & 27 \\
\hline Fingernail pinched/gouged & 15 & - & - & 15 \\
\hline Incised & 7 & - & 3 & 10 \\
\hline Punctate & 4 & 5 & - & 9 \\
\hline Parallel rib paddle impressed & 50 & 185 & 4 & 239 \\
\hline Cross-hatch paddle impressed & - & 19 & - & 19 \\
\hline Diamond paddle impressed & 20 & 1 & 一 & 21 \\
\hline Notched lip: single impression & 94 & 12 & 3 & 109 \\
\hline Notched lip: alternate side & 2 & 11 & - & 13 \\
\hline Other lip application & - & 5 & - & 5 \\
\hline Total & 226 & 238 & 15 & 479 \\
\hline
\end{tabular}

Note: End and side tool impression, fingernail pinching, and punctates generally occur above the shoulder. 
appearance of overlap between the two ceramic assemblages. At the same time, even a cursory review of the three ceramic tables reveals distinct differences. These differences, I argue, are representative of highly divergent ceramic suites.

The Navatu ceramic assemblage is less than a third of the size of that from the Plainware component, a situation potentially related to duration of the occupation. The dominant diagnostic vessel form is a well-made, thin-bodied, hard, globular jar with rounded shoulders and a flaring everted rim with a relatively sharp and well-defined neck-to-rim angle (Table 2; Figure 5). Categorized by Birks $(1973: 41)$ as Vessel Type 1E, the lip on this vessel has a high incidence of crenellation or side-tool notching, while fingernail pinches, incision, carved paddle impression, and other decorative applications frequently occur on the shoulders. Over half $(n=37)$ of the recovered rim sherds for these vessels in 2000 were slipped with a red clay wash. The 2000 excavation recovered only one vessel where the rim could be restored to gain secure quantitative data (Figure $5 d)$. Birks (1973:130-137), however, was able to reconstruct eight vessels and his measurements illustrate a range of sizes for the form (Figure 5). This includes an overall height of $20.8-39.0 \mathrm{~cm}(\bar{x}=32.7 \mathrm{~cm})$, a maximum body diameter of $20.8-39.0 \mathrm{~cm}(\bar{x}=39.6 \mathrm{~cm})$, and a maximum aperture diameter of $15.9-25.0 \mathrm{~cm}(\bar{x}=19.9 \mathrm{~cm})$. This vessel type was the only one identified with a temper other than lithic, alternatively including crushed shell (20 percent of rim sherds) or a mixed temper of calcareous and mineral sands (28 percent of rim sherds). Since shellfish and calcareous sand are absent on the Sigatoka beachfront, either the temper or the pot was transported to the site from elsewhere.

Other jar and bowl types occurring in the Navatu assemblage have a full continuum of rim course profiles from everted to inverted forms. Based on recovered body sherds and a limited number of rim pieces, it is known that some of these vessels were decorated (Figure $5 f$ ). Decorative applications include end and side tool impression, fine line and grooved types of incision, finger pinches, finger gouging, as well as parallel rib and diamond-shaped paddle impression (Table 3). Elsewhere on the dune front, large, heavy, and roughly finished leaf-impressed and mat-impressed trays dominate the Level 2 Navatu assemblage. A small number of tray pieces were recovered from the 2000 excavation $(n=3)$, but this relative absence serves as an anomaly to be examined later. Finally, beyond the jar and tray vessel types and decorative applications, the Navatu ceramic assemblage is distinct because of the absence of handled vessels, simple spouted vessels, and pottery disks, ceramic forms that are present in the Plainware component (Table 1).

Subglobular jars with slightly everted to slightly inverted flattened rims and a rounded or obtuse angled neck to rim juncture are characteristic of the Fijian Plainware assemblage, with some having parallel rib or cross-hatch paddle impression on their surface (Figure 6). Several also have distinctive horizontal striations on the neck as a result of wiping with a coarse fiber. A single vessel recovered in 2000 was sufficiently complete to project a height of $39 \mathrm{~cm}$, a maximum body diameter of $37 \mathrm{~cm}$ and an aperture of $25 \mathrm{~cm}$. These measurements are in approximate line with the two specimens reconstructed by Birks (1973:138). Also abundant in the excavated Plainware component at Sigatoka is a short-necked $(<2 \mathrm{~cm})$ jar with rim profiles ranging from slightly inverted to slightly everted. Plainware bowls similarly incorporate a variety of rim profiles, with the largest group having 


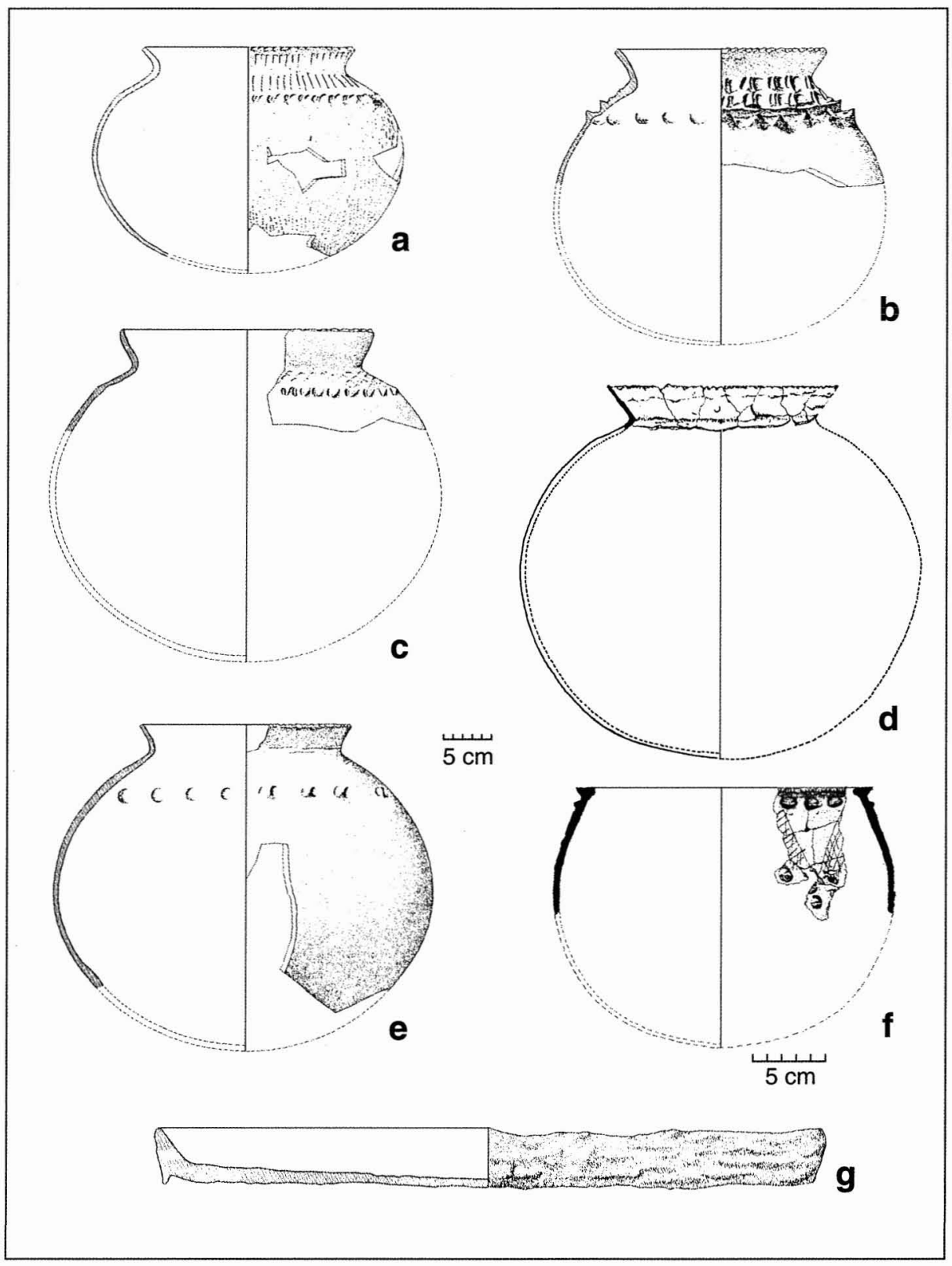

Fig. 5. Navatu phase ceramic vessels: $a-c$, $e$ : Navatu everted globular jar with notched rims excavated by Birks (1973); $d$ : Navatu everted globular jar with notched rim excavated in 2000; $f$ : incised and end tool impressed bowl excavated in 2000; $g$ : salt tray excavated by Birks (1973). All vessels except $f$ relate to the central scale.

direct inverted rims (Table 2). A large, everted thickened rim bowl, while not overly abundant $(n=25)$, appears diagnostic of the Plainware phase. Typically this form has a rim diameter of up to $55 \mathrm{~cm}$, a depth of up to $20 \mathrm{~cm}$, and a rim thickness of up to $1.5 \mathrm{~cm}$. A small number of inverted rim bowls $(n=4)$ have 


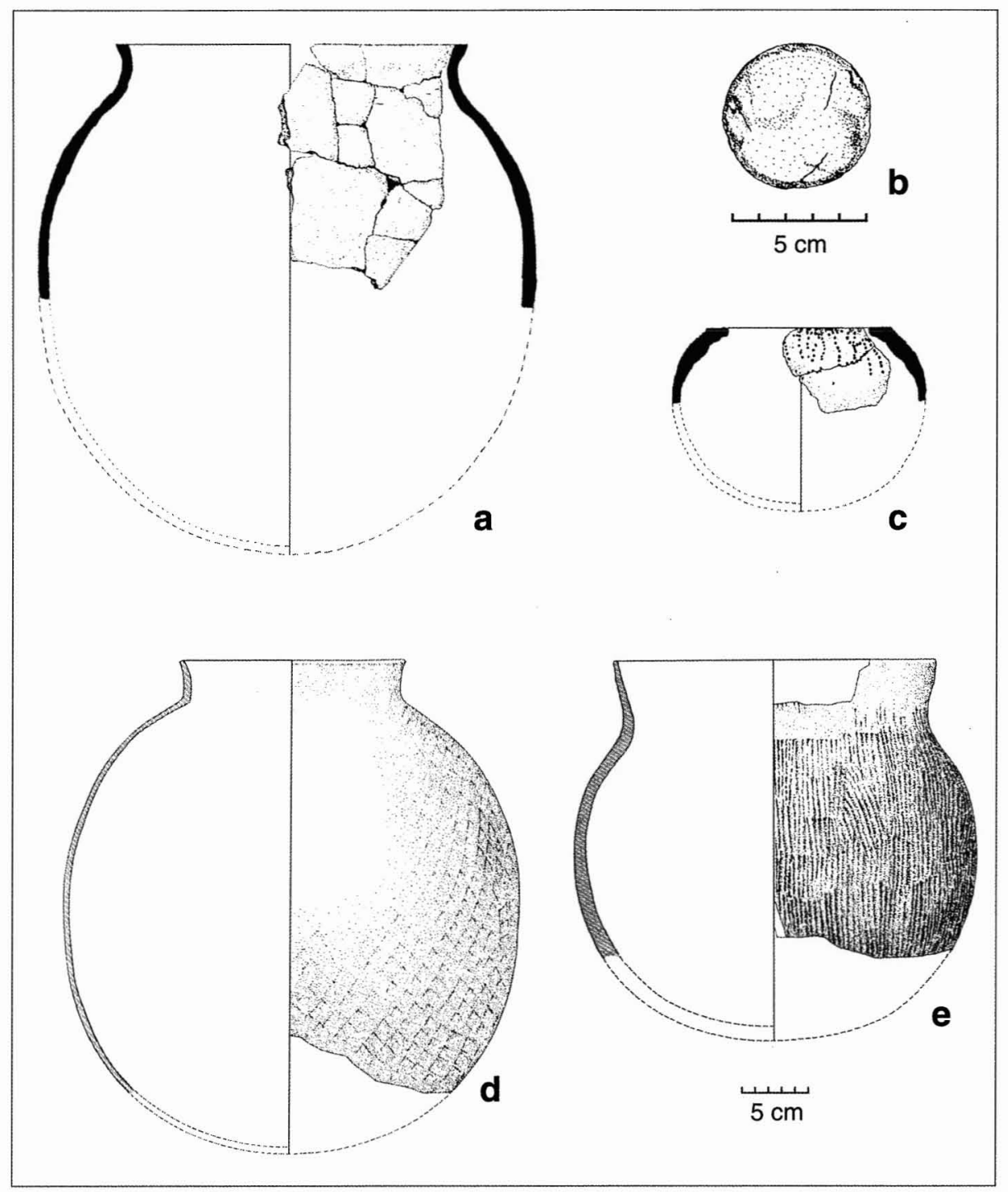

Fig. 6. Fijian Plainware phase ceramic vessels: $a$ : everted rim jar excavated in 2000 ; $b$ : ceramic disk excavated in 2000; $c$ : inverted bowl with punctate decoration excavated in 2000; $d$, e: everted rim jars with paddle impressed surfaces excavated by Birks (1973). All vessels except $b$ relate to scale in bottom right corner.

shoulder carinations, a trait also present on bowl and jar forms within early and late Lapita phase assemblages from the site (Burley and Dickinson 2004).

The ceramic assemblage has been labeled Fijian Plainware but limited decoration does occur on some vessels. A small number of sherds have been decorated using punctates (Figure $6 c$ ), others have cross-hatch and parallel rib paddle impression, and several have notching on the rim (Table 3). The punctate sherds are of particular note for the technique has its closest similarities in Mangassi ceramics 
Table 4. Nonceramic Artifacts Recovered from Navatu and Fijian Plainware Phase Occupation Floors during the 2000 Sigatoka Sand Dunes Excavation PROJECT

\begin{tabular}{lccr}
\hline & NAVATU & PLAINwARE & TOTAL \\
\hline Bone & & - & \\
Bead & 1 & - & \\
Shell & & - & 4 \\
Bead & 4 & & 1 \\
Adze & 1 & 2 & 2 \\
Lithic & & 2 & 3 \\
Adze & - & 3 & 5 \\
Adze flake & - & 1 & 3 \\
Pebble tool & 2 & 7 & 10 \\
Hammerstone & 3 & 9 & 9 \\
Flake & - & 1 & 4 \\
Core/fragment & 1 & - & 2 \\
Pumice abrader & 3 & 25 & 44 \\
Abrader & 2 & & \\
Unidentified & 19 & & \\
Total & & & \\
\hline
\end{tabular}

of comparable age in Vanuatu sites (Bedford 2000). Paddle-impressed ceramics similarly have an earlier appearance in central island Melanesia, in this case in Podtanean wares of New Caledonia (Sand 1996). The use of carved paddle impression as a decorative application has been equated with the Navatu Phase in Fiji (Best 1984; Dickinson et al. 1998; Frost 1979). Hunt (1986:26), however, previously identified this trait on earlier Plainware vessel forms at the Yanuca site approximately $10 \mathrm{~km}$ to the northwest of Sigatoka.

The 2000 project nonceramic assemblage is not overly large $(n=44)$ but, with a density of slightly over 1.8 per $\mathrm{m}^{2}$, it is abundant in comparison to other excavation projects at the dune. Perhaps more important than density is the diversity of items recovered (Table 4). These range from shell and bone beads to abrasive stones, to adzes, to a full suite of materials indicating the presence of flaked stone technology. The latter, for the most part, is based on a bipolar core reduction strategy. Significant variation between upper and lower components is difficult to argue. The array of items, nevertheless, seems characteristic of living floors in which a variety of tasks were being undertaken.

Preliminary sorting of faunal remains by component illustrates a large difference in relative numbers between Navatu and Plainware occupations both for bone and shellfish assemblages (Tables 5 and 6). Rather than differential preservation, this skew seems more likely a result of sampling differences where different activity zones were encountered within each of the occupation floors. The presence of pig in the Plainware component also may help to explain a more limited frequency of fauna, pigs being notable scavengers in and around habitation areas. While the size of the faunal assemblages limits a conclusive comparative analysis for the components, there do exist some intriguing associations and variations (Table 5). First, the presence of pig and chicken in Plainware appear as likely 
Table 5. Provisional Identifications of Fauna Recovered from Navatu and Fijian Plainware Phase Occupation Floors during the 2000 Sigatoka Sand Dunes Excavation Project

\begin{tabular}{|c|c|c|c|c|}
\hline & NAVATU & PLAINWARE & MIXED & TOTAL \\
\hline Fish & 1,047 & 120 & 14 & 1,181 \\
\hline \multicolumn{5}{|l|}{ Mammal } \\
\hline Human & 11 & 3 & - & 14 \\
\hline Pig & - & 2 & - & 2 \\
\hline Dog & 1 & - & - & 1 \\
\hline Sea turtle & - & 2 & 6 & 8 \\
\hline Fruit bat & 4 & 1 & - & 5 \\
\hline \multicolumn{5}{|l|}{ Bird } \\
\hline Indigenous & 8 & 2 & - & 10 \\
\hline Chicken & 1 & 2 & - & 3 \\
\hline \multicolumn{5}{|l|}{ Reptile } \\
\hline Pacific boa & 27 & - & - & 27 \\
\hline Iguana & 4 & - & - & 4 \\
\hline Lizard/gecko & 2 & - & - & 2 \\
\hline \multicolumn{5}{|l|}{ Rodent } \\
\hline Rat: praetor & 87 & 5 & 3 & 95 \\
\hline Rat: exulans & 43 & 5 & 3 & 51 \\
\hline Total & 1,235 & 142 & 26 & 1,403 \\
\hline
\end{tabular}

Note: Faunal sorting was done by David Steadman, Florida Museum of Natural History.

indicators of a horticultural-centered settlement. At the same time shellfish, sea turtle, fruit bat, indigenous birds, and fish, including at least one larger pelagic species, illustrate a range of additional foraging activities. Other than being more abundant, the Navatu component is qualitatively different. Fish dominate the collection, but they consist almost entirely of very small species. This pattern is replicated in shellfish (Table 6), where a great diversity in reef species occurs, but Rissoidea, a gastropod too small for meat extraction, dominates. And unlike shellfish in the Plainware assemblage, economically viable species of gastropods such as Tectus and Turbo are undersized. When one adds in the reptile component of Pacific boa, small iguana, and lizard, it can be suggested that Navatu peoples foraged widely and collected a diverse range of foods while living on the Sigatoka beachfront. This assemblage, in fact, has the hallmarks of a people facing food stress. Finally, human remains, including small bone fragments and teeth, were recovered from both occupation floors. None have taphonomic indicators to suggest they were part of either component's larder.

The 2000 excavation project provides several insights into the mid-sequence occupation of Sigatoka. It documents individual settlements for the Navatu and Plainware phases as well as their associated ceramic complexes. Because there is an intervening sand buildup of $10-15 \mathrm{~cm}$ between these components, each represents a separate abandonment episode occurring sometime between 450 and 650 C.E. This date is the same approximate interval predicted by Dickinson et al. (1998:26) and de Biran (2001:111) for the onslaught of sand accumulation on the eastern end of the dunes. Of the two occupations, the Plainware phase settle- 
Table 6. Shellfish Counts for Two i $\times$ i M Units (Units I4-K and I $5-F$ ) Excavated during the 2000 Sigatoka Sand Dunes Project

\begin{tabular}{|c|c|c|c|}
\hline & NAVATU & PLAINWARE & TOTAI \\
\hline \multicolumn{4}{|l|}{ Gastropods } \\
\hline Turbo sp. & $164(14.2)$ & $66(57.9)$ & 230 \\
\hline Tectus pyramis & $22 \quad(1.9)$ & - & 22 \\
\hline Cypraea tigris & $3 \quad(0.3)$ & - & 3 \\
\hline Cypraea sp. (small) & $53 \quad(4.6)$ & $12(10.5)$ & 65 \\
\hline Conus sp. (small) & $28 \quad(2.4)$ & $2 \quad(1.8)$ & 30 \\
\hline Thais sp. & 21 & - & 21 \\
\hline Cerithiumnodulosum & $9 \quad(0.8)$ & - & 9 \\
\hline Phalium sp. & $9 \quad(0.8)$ & - & 9 \\
\hline Nerita sp. & $5 \quad(0.4)$ & - & 5 \\
\hline Bulla sp. & - & $1 \quad(0.9)$ & 1 \\
\hline Rissoidea sp.* & $593(51.2)$ & $8 \quad(7.0)$ & 601 \\
\hline Litorina sp.* & $40 \quad(3.5)$ & - & 40 \\
\hline Strombus mutabilis* & $31 \quad(2.7)$ & $8 \quad(7.0)$ & 39 \\
\hline Cymatium sp.* & $2 \quad(0.2)$ & - & 2 \\
\hline Oliva sp.* & $1 \quad(0.1)$ & - & 1 \\
\hline \multicolumn{4}{|l|}{ Bivalves } \\
\hline Anadara sp. & $8 \quad(0.7)$ & $2 \quad(1.8)$ & 10 \\
\hline Batissa sp. & $168(14.5)$ & $15(13.2)$ & 183 \\
\hline Pictada maculata & $1 \quad(0.1)$ & - & 1 \\
\hline Total & 1,158 & 114 & 1,272 \\
\hline
\end{tabular}

Notes: Shellfish identification was done by Andrew Barton, Simon Fraser University.

* Identifies species employed as a mix for broth since individual specimens are too small for meat extraction. Numbers in parenthesis are relative percentages for phase assemblages.

ment appears the longest lasting and most stable. This interpretation is supported by the limited faunal data suggesting horticulture as well as the sheer density of ceramics that had accumulated on the living surface (Table 1). The Navatu Phase occupation seems more ephemeral, with a subsistence economy characterized by a wide-ranging foraging spectrum.

Why the Navatu people chose to reoccupy the Sigatoka River mouth possibly in the face of blowing sand can be resolved through an understanding of Level 2 ceramics occurring in the paleosol to the west. Here, as noted, dense concentrations of crudely finished trays occur, many in association with the prototypic Navatu jar. These trays have a diameter in excess of $60 \mathrm{~cm}$, and weigh $2 \mathrm{~kg}$ or more (Figure $5 g$ ). Based on surface features recorded in 2002, including a basketsized concentration of unfired clay in one of these concentrations, it is believed that the trays were formed, fired, and used in situ. Birks (1973:45) came to a similar conclusion, noting that in size, characteristics, and weight, they were impossible to transport over any distance. Birks raises several possibilities as to the function but clearly proffers their use as evaporation pans for the production of sea salt (also Marshall et al. 2000:89). A 2002 transevaporation experiment using Sigatoka seawater in a replicated tray demonstrates their capability for this task. If the trays were used for salt, then their relative absence in the excavated habitation site indicates that salt production was being carried out in specialized processing areas. Sea salt is documented as a critical trade item moving from the coast up the 
river systems to interior highland communities in the historic period (Williams 1858:94; Tonganivalu 1917:9).

\section{THE LEVEL 2 PALEOSOL RECONSIDERED}

Both the Fijian Plainware and Navatu phase ceramic assemblages occur in a period of time that is consistent with the development of the Level 2 paleosol in other parts of the dunes. Birks (1973) did not identify a stratigraphic separation between the two and he combined Navatu and Fijian Plainware vessels as a single assemblage (also Marshall et al. 2000:6). Gone unrecognized, this has caused confusion for archaeologists since some of the Plainware rim forms correspond with late Lapita types associated with Level 1.

The Level 2 paleosol is described by de Biran (2001:51) as an inceptisol, including well-defined A and B horizons over unconsolidated siliceous parent material. It can be traced for a distance of no less than $1.2 \mathrm{~km}$ along the dune front with elevations described by Marshall et al. (2000:24) as rising toward the west. In July 2002, a $2 \times 1 \mathrm{~m}$ test unit was dug into an exposure of this paleosol with dense concentrations of salt tray sherds. The unit was located approximately $440 \mathrm{~m}$ west of the 2000 excavation block and $3.65 \mathrm{~m}$ elevation above extreme high tide. It revealed a well-formed soil structure with a very compacted blackbrown sandy silt A-horizon of $35 \mathrm{~cm}$ thickness. Darker veining occurs throughout, a feature possibly related to illuviation and moisture seep. A dark brown sand B-horizon approximately $40 \mathrm{~cm}$ in thickness occurs below, followed by a $\mathrm{C}$-horizon of olive green sand (moist). The tray concentration, including intentionally stacked broken pieces, was limited to the upper A-horizon with no other cultural materials recovered from the excavation. The well-formed nature of the paleosol and its organic content indicate a high degree of surface stability that may have been enhanced through a forest cover of Casuarina litoralis (Best $1989: 48)$. Stands of this tree presently grow further to the west on stabilized and protected dune surfaces.

Armed with a new understanding of Level 2 ceramic complexes, a reexamination of dune front ceramic scatters was conducted in July 2002, extending from the main excavation area to approximately $1 \mathrm{~km}$ west. This survey located several exposures of the Level 2 paleosol in association with spatially discrete clusters of Navatu or Fijian Plainware ceramics, as well as other clusters that occurred on a fully deflated surface. In the small number of cases where the two ceramic complexes appeared mixed, the Navatu sherds illustrate a higher degree of weathering, suggestive of at least limited super positioning within the paleosol. Elevations and GPS coordinates were recorded for the paleosol and related ceramic clusters at six separate locations from approximately $300 \mathrm{~m}$ to $750 \mathrm{~m}$ west of the excavation area. Like Marshall et al. (2000), elevations were found to undulate widely, in this case between 1 and $9.8 \mathrm{~m}$ above high tide for Level 2 exposures. Seemingly even more confusing was the occurrence of Navatu phase ceramics at an elevation of only $1 \mathrm{~m}$, while $20 \mathrm{~m}$ to the west, Plainware ceramics were present at $6.7 \mathrm{~m}$, giving the appearance of a completely upside-down stratigraphy. Despite its anomalous appearance, these distributions prove informative; they illustrate clearly that the paleosol did not form on a back beach sand flat as previously reported by Dickinson et al. (1998:12). Rather, it developed over a slope rising 


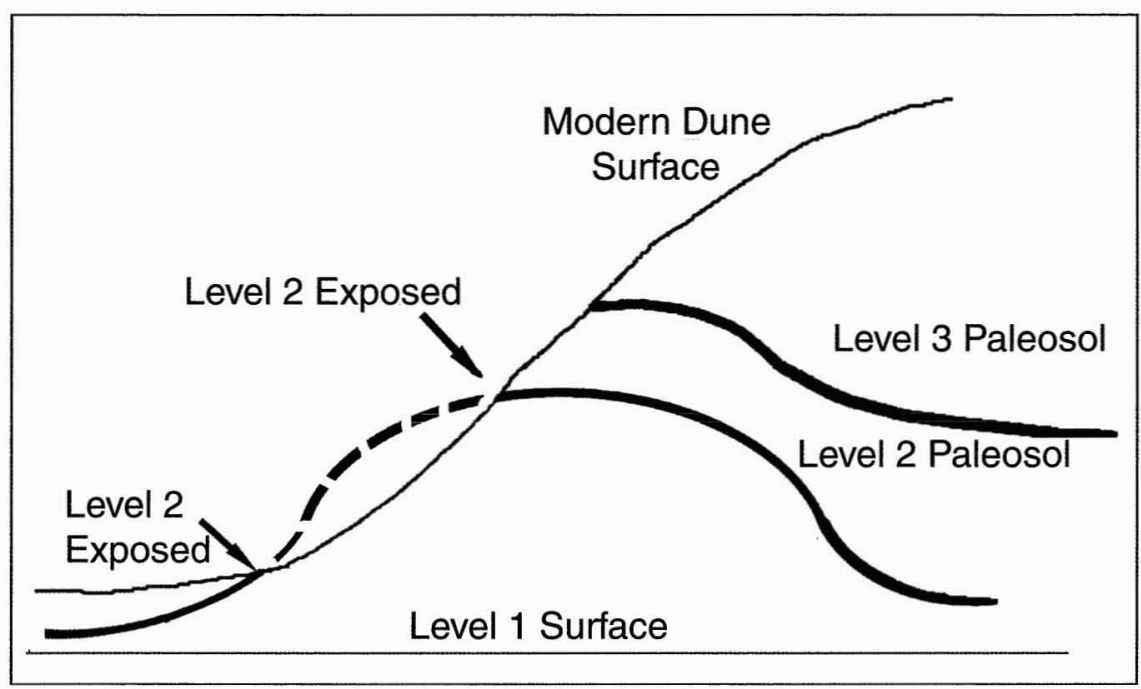

Fig. 7. Hypothetical erosional face of the eastern end of the Sigatoka Sand Dunes, Viti Levu, Fiji, with lower and higher Level 2 paleosol exposures.

inland to a probable height of from 10 to $11 \mathrm{~m}$. Variable elevations for Navatu and Plainware ceramics are a function of their original position on that slope, not a consequence of vertical separation due to dune formation. Complete erosion of Level 2 along the dune front mid slope also provides a confusing situation where the paleosol is exposed at an elevation of $1 \mathrm{~m}$ or less, and then reexposed at 8 or 9 $\mathrm{m}$ elevation upslope and directly inland (Figure 7). In this context there is little wonder why archaeologists have become perplexed attempting to interpret the number and nature of paleosols at Sigatoka.

The formation of the Level 2 paleosol over a slope begs the question of earlier dune formation as inferred by Marshall et al. (2000:54-62). Here it is important to note that the slope could have formed only after ca. 500 B.C.E., when the late Lapita Level 1 ceramic occupation had become buried. Excavations into the Level 1 ceramic floor in 1998 and 2000 illustrate that it occurs on a horizontal plane running directly into the dune face between 2 and $2.5 \mathrm{~m}$ elevation above high tide (Burley and Dickinson 2004). Unlike Level 2, this conforms well to the interpretation of Dickinson et al. (1998:12) where Level 1 was correlated with a back beach sand flat protected from the open shore by a low eolian dune over top of a beach berm. The sand intervening between Levels 1 and 2 further incorporates a layer of paleo-beach pumice, meaning that the area was exposed to storm waves, at least in the initial stages of slope formation. The longshore, linear, beach-facing orientation of the Level 2 slope, rather than the strongly oblique trend of the modern dunes, also is indicative of a beach berm. Windborne sand ultimately would cap this ridge and build it inland, with the crest occurring at 10-11 m. Excavation profiles by Marshall et al. (2000:100) and Birks (1973:16) appear to illustrate the crest and back slope of this feature, respectively. A dune front subsurface profile derived from ground penetrating radar by de Biran (2001: 115) similarly documents a back slope grade. 


\section{LEVEL 2 CEMETERIES IN PERSPECTIVE}

In 1986, Fiji Museum personnel recorded a series of low coral mounds eroding from Level 2 on the eastern end of the dunes. Excavation into one of these found human remains, indicating that the mounds were burials interred in coral rock cairns. Excavations in 1987 and 1988 by Best (1987a, 1989) revealed the presence of a structured cemetery including twenty cairns, several with multiple interments, as well as other interments without cairns scattered within and around the perimeters. The cemetery was situated on a low, mounded rise, with the most elaborate cairns occurring at the highest elevations. In total fifty-five individuals of both sexes and all age groups were recovered (Visser 1994). Burials were flexed to semiflexed with orientation almost rigidly east/west with head to west. Less precision in orientation and other variations in burial practices were found among a group of "unusual" interments on the northern perimeter. Four cairn burials had grave goods, and another had four large paddle-impressed ceramic fragments placed over its head as a cover. Based on differential elaboration and elevations for the interments, Best $(1989: 58)$ concluded that the cemetery had been used over a number of years by a highly stratified society. Visser (1994) and Pietrusewsky et al. (1994) undertook osteological and comparative analyses of the human remains.

The presence of a structured cemetery $50 \mathrm{~m}$ to the southwest of the $2000 \mathrm{ex}-$ cavation area can be understood in light of Plainware and Navatu settlement locales. The question needing to be answered is, to which of the settlements does the cemetery relate? Because the pottery head cover had cross-hatched paddle impressions, Dickinson et al. (1998) assumed it diagnostic of the Navatu phase. That association no longer is predetermined, as cross-hatch paddle impression is part of the Fijian Plainware ceramic suite at Sigatoka as well. The evidence now suggests the Plainware community as the most likely candidate for origins of the cairn burial complex. First, the only two radiocarbon dates in association with the cemetery long predate the Navatu phase occupation as herein defined. One of these dates, $1870 \pm 80$ B.P. (WK 996b) was taken on human bone from a skeleton interred in a cairn. The other date of $1680 \pm 60$ B.P. (NZ 7599) is from a tree stump believed growing on the mound during use of the cemetery (Dickinson et al. 1998:47-48). Second, the Plainware settlement appears as a longer term and more economically stable community than Navatu, one compatible with the degree of elaboration afforded the dead within the cemetery. And finally, Visser's (1994:ii) comparative analyses of the human remains suggests a close affinity between the Sigatoka population and "Lapita associated skeletons," as well as most Polynesian groups. This affinity is replicated in Fijian Plainware ceramics, where continuity in ceramic manufacture can be traced back through late Lapita to the early Lapita period.

Following Best's cemetery excavations, additional Level 2 burials were exposed on the eastern end of the dunes and recorded or excavated by various researchers (Burley 1997; Crosby 1991; Hudson 1994). Marshall et al. (2000:49-50) interpret one group of these remains as a second burial ground, $200 \mathrm{~m}$ to the west of the cairn burial complex. This cemetery had an area measuring no more than $25 \times 15 \mathrm{~m}$ but once contained at least twenty individuals and possibly more. Burials were interred exclusively in pits without cairn overlays, both as individuals 
and as multiple groupings. East/west orientation is present, but others were aligned with head to north (Hudson 1994) or south (Burley 1997). The differences in mortuary patterns between this cemetery and the one to the east are noteworthy, and at least circumstantial evidence for the western burial ground suggests it has an association with the later Navatu period. For example, a large fragment of an elaborate Navatu style bowl was recovered from the fill of a burial pit in which at least three individuals were present (Burley 1997:42-45). From the 1991 excavation of another multiple interment, in this case including three adult females and an adult male, Marshall et al. (2000:110) associate it with the end of the Level 2 occupation period. And Visser's (1994:193-194) comparison of these latter individuals with those to the east seems equally telling. With all due caution stated for sample size, the limited number of traits that could be compared, and bone degradation, he reports their potentially closer phenotypic relationship with more recent Fijian skeletal remains.

The burial patterns that differentiate the western cemetery are similar to those Best used to discriminate his unusual burials from the main cairn complex. This raises the possibility that the eastern cemetery includes a temporally mixed as well as a socially diverse group. This applies particularly to a series of pit interments that occur on the outer fringe of the main complex where burial alignments are less precisely configured than is the case with cairns (Best 1989:37). One (B25), for example, is facing west with head positioned to the east while another (B1/1) has head to the northwest facing southeast. In his analysis of the group of female interments along the northern periphery, Visser (1994:177) identified four as having enamel hypoplasia, a stress marker potentially related to poor nutrition, vitamin $\mathrm{D}$ deficiency, or infection. Comparing these women with others from the cemetery, he further notes the presence of traits indicating a demanding use of the upper body (Visser 1994). Both features support interpretations of a lower status for these women but might equally relate to a Navatu population under food stress, and one engaged in a salt production operation that required continuous pottery manufacture and transport of clay to the beach front.

\section{THE IMPLICATIONS OF THE SIGATOKA DATA FOR MID-SEQUENCE CULTURE HISTORY IN FIJI}

The break between the Fijian Plainware and Navatu phase ceramic complexes at Sigatoka appears distinct and abrupt. The evidence indicates independent episodes of occupation and abandonment by groups having different ceramic complexes. At the same time, the occupations are closely spaced in time with an abandonment interval of perhaps as little as a century. Understanding the nature of this transformation contributes to and has implications for several ongoing debates in Fijian archaeology. Among these are questions of long-distance migration, population continuity or replacement, external versus internal stimulated culture change, and linguistic and phenotypic variation within Fiji (Best 1984, 2002; Clark 1999; Geraghty 1983; Hunt 1986, 1987; Kirch 2000; Kirch and Green 2001; Marshall et al. 2000; Rechtman 1992). These concerns are of critical importance to understanding Fijian people and society as manifest historically and at present. 
There is little doubt that Fijian Plainware ceramics are related to and derive from earlier Lapita occupations in Fiji. The thickened everted rim bowl, smaller jar types, handled vessels, notched rims, limited retention of shoulder carination, pottery disks, construction techniques, and other features illustrate clear affinities to late Lapita Level 1 ceramics excavated by Birks (1973; also Burley and Dickinson 2004). Change has occurred, but this is to be expected given almost a millennium of pottery manufacture between the two assemblages. The Level 1 ceramic assemblage in turn clearly relates to an earlier Lapita phase at the site and elsewhere (Birks 1973; Burley and Dickinson 2004; Marshall et al. 2000; Petchey 1995). Sigatoka thus provides a sequential series of insights or time slices into a 1500-year-long continuity in pottery manufacture. This sequence, in keeping with Green's (1963) chronology for Fiji, has been labeled the Sigatoka phase. The duration of this concept unfortunately masks sequent technological and stylistic change in ceramic production as well as other aspects of culture. A more appropriate approach, and one sensitive to and defined by the data from Sigatoka, is to treat this phase as a tradition, with cultural continuity back to initial Austronesian settlement. A Sigatoka tradition inclusive of early Lapita, late Lapita, and Fijian Plainware phases facilitates a more refined ceramic chronology for comparative analyses in time and space.

Based on his analysis of ceramic assemblages from Yanuca, Hunt (1980, 1986) previously proposed a Yanuca phase. The ceramic forms associated with this phase (Hunt 1980:127-136) are all but identical to those described as Fijian Plainware at Sigatoka. Rather than basing the Yanuca phase on a full assemblage of vessel forms and traits, however, Hunt defined it as the "simple addition" of carved paddle impression to "Lapita plainwares" (Hunt 1986:26). With this addition the phase then was argued as transitional, where earlier Lapita vessel forms could be linked to carved paddle-impressed pots of Navatu and later periods. In fairness to Hunt, temporal distinctions of different assemblage types within Green's Sigatoka phase had yet to be made, and stratigraphic mixing at Yanuca gave the impression of a much earlier age for the introduction of paddle impression. Carved paddle impression, nevertheless, is only one of many traits that occurs within a Fijian Plainware assemblage, and continuity in the use of this decorative application does not corroborate continuity in ceramic tradition. Indeed Hunt's (1980:9091, 95-96) own data tables from Yanuca illustrate a Plainware/Navatu break as distinct as that at Sigatoka. My choice of the term "Fijian Plainware" rather than "Yanuca phase" avoids the confusion of a transitional stage defined exclusively by carved paddle impression.

Beyond Yanuca, a comparison of Plainware ceramics from Sigatoka with temporally related assemblages in Fiji and western Polynesia finds similarities but also important differences. In stylistic terms, one of the closest analogues comes from Ugaga, a small island offshore from Beqa, west of Viti Levu. Initially recorded by Crosby (1988:115), the site had an interesting mix of paddled impressed and mid-sequence rims. More recent excavation by Clark (1999), unfortunately, illustrates heavy disturbance with a frustratingly mixed ceramic collection. Yet Clark's descriptions and illustrations of several Ugaga ceramic forms strongly replicate Fijian Plainware types at Sigatoka, including different variations of paddle impression. Applying a multidimensional scaling analysis to seriate vessel types, Clark 
(1999:188) eventually was able to separate the Plainware types as a temporal group, identifying them as closely related to Lapita forms and distant from Navatu ones $(1999: 185)$.

Comparisons beyond Fiji to Plainware ceramics in Tonga, Samoa, Futuna, and Uvea provide a contrast to the west Fijian assemblages. Polynesian Plainware complexes vary subtly between archipelagoes, in keeping with regional developments of ancestral Polynesian societies (Kirch and Green 2001). At the same time, they share a highly common pattern characterized by a reduction of diversity in vessel forms and types, and an increasing deterioration in manufacturing techniques (Burley 1998; Green 1974; Sand 1990, 1998). In Tonga, for example, Polynesian Plainware ceramics after 1 C.E. are restricted to but a single large subglobular jar and a very small number of bowls (Burley 1998). By 400 C.E. when the Sigatoka ceramics were being manufactured, ceramic production had all but ceased in West Polynesia. Fijian Plainware ceramics at Sigatoka not only incorporate a range of vessel forms and a reasonable level of expertise in manufacture, but there seems to be increasing diversity when compared to the late Lapita phase of Level 1. The introduction of spouted vessels is particularly notable, as also the use of carved paddles and punctates to add surface decoration.

The retention and diversification of ceramic production in west Fiji are important hallmarks, for a similar pattern of diversification can be seen in different parts of Melanesia at approximately the same period of time (Bedford 2000; Sand 1995). Combined with the earlier presence of both punctate and paddle impressed wares to the west, it is possible to argue for the intrusion of ceramic influences from central island Melanesia. This statement does not promote migration as an explanation. Rather, given continuity in Fijian Plainware ceramic trends with earlier Lapita wares, it more likely is the result of occasional contacts through interisland voyaging, a type of interaction that could well extend back to the initial settlement period in Fiji.

The ceramic sequence of Lakeba, in Lau, is among the most complete, well dated, and well defined of any in Fiji or West Polynesia. Lau is positioned intermediate between Fiji and Tonga, and Best (1984) convincingly demonstrates changing patterns of interaction with both areas at different periods in prehistory. From initial settlement up to approximately 500 B.C.E., the ceramics of Lau are in close sequence with those of West Polynesia. This includes Period I, an early eastern Lapita ceramic phase that, through loss of decorative application and with a reduction in the number of vessel forms, is transformed into Period II, a ceramic suite equated with Polynesian Plainware (Best 1984:635). By ca. 100 B.C.E., parallel-rib and cross-hatched paddle-impressed ceramics begin to appear, and these define the beginning of Period III. This period, according to Best (1984:654) has the biggest ceramic break in the sequence, covering vessel form, $\mathrm{rim} /$ lip shape, as well as type and volume of temper. This assemblage is markedly different from the earlier Polynesian Plainware in Lau, and those simultaneously occurring in Tonga and Samoa. Lau had now swung back to a Fijian interaction sphere. At ca. 200 C.E., the additional traits of asymmetric incising, finger pinching, and rim notching occur. These are accompanied by obsidian from Vanuatu (Best 1984:655). Because the traits are rare, there is a consistent use of carved paddle impression, and vessel forms overlap, the new suite of decorative traits is 
integrated within Period III of the Lau sequence rather than signaling a break. Period III in Lakeba is compared by Best $(1984: 635)$ to the Navatu phase, and it continues to about 900 C.E.

Best no doubt is correct in his interpretation that paddle-impressed wares in Lakeba signal a major transition and a swing in Lakeban prehistory back toward Fiji. The ceramic suite he documents, including vessel form diversity, rim/lip types, and other features, seems highly comparable to the Fijian Plainware assemblage that was developing or had developed in west Fiji. The major differences he describes relative to earlier Lauan Plainware ceramics are of the ilk given in above comparisons of Fijian Plainware to ceramic suites in Tonga, Samoa, and Futuna/ Uvea. A regional variation in ceramic production, one developed elsewhere in Fiji, finally reached Lau. Equally important to note is that, despite the rarity of such traits as asymmetric incising and finger pinching, they represent more than a simple introduction of new decorative techniques to the Lakeban sequence in Period III. Best's (2002:20) seriation chart of temper types, for example, illustrates a complete transition from lithic to calcareous tempers at exactly the same time. This change seems as abrupt as the one he documents for the onset of paddle-impressed wares some 300 years earlier. His seriation chart for vessel shape and rim (Best 2002:19) form illustrates still other changes occurring simultaneously. Most significant in these is the sudden appearance of kuro, a cooking pot with sharply everted rims, that then continues onward in Lakeba to the historic era. The break at 200 C.E. in the Lakeban sequence may well be more definitive than it previously has been made out to be.

The Navatu Phase ceramic complex on Viti Levu similarly is divergent from Fijian Plainware. Admittedly the use of paddle impression continues to be present, and there is overlap in vessel shapes as defined by rim course profiles. The differences, nevertheless, seem significant. In terms of ceramic forms per se, handled vessels and ceramic disks disappear from the assemblage. Large everted bowls with thickend rims, a characteristic of Fijian Plainware, seem rare in Navatu. There is a sudden appearance of the large, expediently finished tray, a vessel type presumed to be used for salt production. There is the introduction of a highly distinct double-spouted vessel, as Clark and Sorovi-Vunidilo (1997) document. There is a sudden concern with ceramic decoration using incision, finger pinches, and gouging as well as side and end tool impression. And there suddenly appears the distinctive Navatu globular jar with standardized everted flaring rim (Figure 7).

The globular jar is noteworthy for more than its overall form. These vessels, as described by Marshall et al. (2000:89) "are beautifully manufactured from local tempers, are extremely thin walled and generally display paddle-and-anvil finishing, if not carved paddle decorations." In keeping with thin walls and wellworked body fabrics, they are hard and well fired. In the 2002 field season, two Navatu period hearths were excavated in which burned and disintegrated coral rock in the form of calcium carbonate clay (slaked lime) was present. The eroding basket-sized concentration of potting clay near a surface exposure of tray sherds on the dune front noted earlier also had degrading coral limestone in its midst. Di Piazza (1998:84) importantly illustrates how calcium carbonate stones, when heated, disassociate to quicklime and then hydrate to slaked lime during cooking. 
This reaction raises temperatures significantly to a minimum of $750^{\circ} \mathrm{C}$ (Di Piazza 1998:86). These temperatures may have been critical for the open hearth firing of the thin-walled jar, if not the range of other Navatu ceramic forms. The jar, then, would not only be a different vessel type in comparison to Fijian Plainware, but a potentially different potting technology altogether.

The decorative system for Navatu phase ceramics applied a range of new techniques. Combined in different ways, they have resulted in elaborate patterns on the upper half of jars and on inverted rim bowls (Figure 7). Best (2002:31) appropriately notes that, while these traits are not particularly complex, they appear in Fiji as a package, without a direct precursor. The full range of vessel forms to which this application was applied has yet to be investigated through site-by-site comparison in Fiji. Yet, as was reported for Lakeba, only a small percentage of the pots were decorated. At Sigatoka, specific applications from tool impressions to finger pinches occur on only 0.6 percent of the Navatu phase nonrim assemblage while paddle impressed sherds at 0.7 percent are in only slightly greater abundance. In the Layer 4 Navatu phase collections excavated by Clark (1999:119120, Tables 12-13) from the Navatu type site, surface decoration other than paddle impression accounted for 4.2 percent of the assemblage; paddle-impressed sherds were significantly more abundant at 17.8 percent. In contrast to body decoration, rim treatments at Sigatoka including notching and crenellations were widely applied, representing 24.5 percent of the Navatu rim assemblage (see Figure 5). At Navatu, Clark (1999:123) describes such treatments as rare.

The nature of the Navatu decorative system in Fiji has resulted in quite varied interpretations as to its origins and implications. Because Clark is unable to find a directly comparable assemblage outside of Fiji, he (1999:219) rejects either a diffusionist or migrationist explanation for its presence. In their stead, and acknowledging the abruptness of the event, he links mid-sequence ceramic change to internal societal developments (also Rechtman 1992). Marshall et al. (2002:90), on the other hand, do not rule out a Melanesian origin for the decorative traits, but downplay their importance for understanding the Fijian past. In this, they categorically state, "the very ephemerality of this decoration suggests it was mere whimsy, perhaps a new idea picked up from Vanuatu, but of no consequence in re-establishing a prestige economy or altering the fundamental basis of Fijian society." Alternatively, Best (1989:60) marks it as a major and significant occurrence, one that in Lakeba seems not just a marker of Melanesian influences or contacts, but an indication that people had arrived from the west. In this view, the decorative system is hardly "mere whimsy."

Best's position is not based on a failure to find comparative evidence, as Clark's is stated to be, nor is it an assertion of theoretical high ground, as is underlying the claims of Marshall et al. (2000:5-10). He is influenced, rather, by the very secure correlation of Navatu decorative applications with twelve flakes of obsidian from Vanuatu sources, eleven of which can be linked to the Vanua Lava or Gaua sources in the Banks Islands. He also is influenced by the fact that, while not completely identical, a comparable system of ceramic decoration does exist in northern Vanuatu, and was recovered by Ward (1979) from a site close to Vanua Lava and only $40 \mathrm{~km}$ from Gaua (Best 2002:30-32). And convinced that a "Vanuatu connection" is real, he offers a possible motive for this transmigration 
to Fiji. The ultimate push factor, in his view, could have been the volcanic eruption of Ambryn, an event resulting in significant ash falls and tsunamis in central and northern Vanuatu.

Navatu decorative traits in Fiji are taken to be widely distributed, rapidly spread, and presumably short lived. Given the existing state of mid-sequence archaeology for the archipelago (Clark 1999:32-34), the relative paucity of welldated radiocarbon sequences, and the quite different approaches applied to ceramic analyses and presentation, an adequate assessment is difficult to make. Certainly the distribution of Navatu decorative traits seems widespread. They are documented not only at Lakeba, Sigatoka, Yanuca, and Navatu, but also at Karobo (Clark 1999) on Viti Levu, Taveuni (Frost 1974) in northeastern Fiji, presumably from Wakaya in the Lomaiviti group (Rechtman 1992:228), and quite possibly from the Yasawas (Hunt et al. 1999) in extreme northwestern Fiji. Clark (1999:236) interprets this distribution as indicative of a Fiji-wide interaction network from which a pan-archipelago society emerged. The Navatu decorative system may have had little impact itself on the fundamental basis of Fijian society, as claimed by Marshall et al. (2000:90), but if Clark is right in his interpretation, it is a critical marker by which to chart the emergence of this society in prehistory.

An evaluation of the ephemeral short-term nature of Navatu decorative application is more difficult to deal with given the limited number of well-dated contexts. At Sigatoka, for example, radiocarbon dates and archaeological deposits illustrate a fleeting occupation. In this case it is ephemeral for reasons described previously, not the result of stylistic change. For Lakeba, Best (2002:32) also opines that it is a momentary phenomenon, describing it as no more than a "short burst" of end tool decoration at approximately 200 C.E. The seriation chart (Best $2002: 20)$ for Lakeba ceramic decorative techniques is contradictory. On that chart asymmetric incising, finger pinching, and various types of paddle impression co-occur at the Qaranipuqa rockshelter at 220 C.E. Archaeological evidence indicates that this rockshelter was immediately abandoned thereafter (Best 1984:78), but the same traits co-occur again at the Laselase rockshelter between 300 and 600 years later. Best's "short burst," then, took place over a period of at least 300 years, and quite possibly a half a millennium or more (possibly up to 900 C.E. as stated in Best 1984:635). Clark's (1999:85) dating of the Navatu phase (Layer 4) deposits at the Navatu site similarly indicates a degree of longevity for associated occupation. His calibrated dates for lower and upper deposits are consistent, providing a bracketing date of 400-1000 C.E. based on calibration curve intercepts.

It is obvious that additional radiocarbon dates from sites throughout Fiji are required before definitive conclusions on the emergence, longevity, and disappearance of Navatu ceramic forms can be drawn. The limited evidence nevertheless indicates that it was not a short-lived stylistic whim in Fijian prehistory. The suite of existing dates suggests further that the earliest appearance of Navatu ceramics took place in Lau by 200 C.E. in tandem with Vanuatu obsidian. The earliest secure dates for Navatu related ceramic deposits on Viti Levu, while overlapping with Lakeba in calibrated ranges, appear later, occurring by 400 C.E. As speculative as it may seem, it can be hypothesized that an east to west time-transgressive settlement and expansion of Navatu related groups or ceramic transmission took place from Lau to western Viti Levu. Thus, at exactly the same time that the 
Navatu site was being founded in northern Viti Levu, a group producing Fijian Plainware ceramics was present at Sigatoka on the opposite side of the island. By approximately 500 C.E. this no longer was the case.

\section{CONCLUSION}

This paper has presented new data and insights into the mid-sequence occupation of the Sigatoka Sand Dunes on the Coral Coast of Viti Levu. These data help resolve a number of long-standing and enigmatic issues on the nature of midsequence occupations, and its distribution in the Level 2 paleosol. Mid-sequence archaeology at Sigatoka is represented by two discrete and superimposed settlements related to the Fijian Plainware and Navatu phases. These occupations have distinct ceramic complexes but radiocarbon dates indicate no more than a one to two century time span between the two.

In addition to a presentation of site data, attempts have been made to compare and explore the implications of the Plainware/Navatu break for Fijian prehistory more broadly. Admitting that the comparative data are less than ideal, a number of patterns appear to be present. First, the break most succinctly is correlated with a sudden appearance in the ceramic assemblage of a distinctive globular jar, large crudely finished trays, and decorative applications including asymmetrical incision, fingernail pinching and gouging, as well as end and side tool impression. The latter traits are documented first in Lakeba, in association with Vanuatu obsidian, leading Best $(1984,1989)$ to hypothesize a corresponding movement of people from the west. Second, during the next two centuries, they occur throughout the remainder of the archipelago but overlap in time with Fijian Plainware at Sigatoka. Third, rather than a short-term presence, as claimed by Best (2002) and Marshall et al. (2000), these and other Navatu traits persist for more than half a millennium. And, finally, from all appearances they provide a foundation for stylistic and vessel form types of the sequent Vuda phase (Frost 1979).

From the time of Dumont d'Urville (1832) Fijians have been recognized as having phenotypic and cultural characteristics consistent with long-term contacts to the west. It was for these reasons that Fijians traditionally have been categorized as Melanesian rather than Polynesian. Even in Oliver's (1989) more recent survey of Oceanic societies, he documents several Melanesian-linked societal features separating Fijians from Polynesians, and implies long-term influences or contacts. Among the more important are a nucleated village pattern of settlement, varied concepts of chiefship, house forms, the presence of men's houses, the use of a temple-like god house, distinctive exchange institutions, and Dravidian kinship terminology (see also Kirch and Green 2001:65-70). Comparative and historical linguistic studies similarly infer multiple settlement episodes and influences at work in Fiji (Pawley 1972; Pawley and Green 1973; Pawley and Sayaba 1971). Geraghty (1983:389) not only suggests that later arrivals were responsible for important linguistic changes but firmly documents the closer affinity of west Fijian dialects with Melanesian languages when compared to Polynesian languages. Finally, while comparative osteology and genetics provide a wide-ranging mix of interpretations, most studies support a degree of population contact with the west and east, while underscoring the complexity of Fijian biological history (Clark 
1999:300). Importantly positioned within this mix are Visser's (1994:249-250) ultimate conclusions on the Sigatoka burial population, one that is linked herein to a Fijian Plainware phase. This group, he infers, differed in body form and craniofacial form from later Fijians, suggesting both "later intrusive contact" and "a source of new genetic material in Fiji."

In spite of overwhelming data in support of Fijian/central Melanesian interactions and probable migration(s) in prehistory, virtually all recent Fijian archaeologists other than Best caution profusely against the use of ceramic data to infer such events. They also assert long-term models of population continuity in which culture change, including ceramics, is to be explained exclusively by internal social, political, or adaptive variables (Clark 1999; Crosby 1988; Hunt 1986, 1987; Marshall et al. 2000; Rechtman 1992). To propose otherwise constitutes theoretical heresy (Marshall et al. 2000:1-8). Yet, as Best (1984:663) concludes after his detailed analysis and presentation of data from Lakeba, there is nothing out of the ordinary in the movements of people over great distances in Oceania, and nothing demeaning if a recipient culture is affected by the arrivals. These types of interactions and societal impacts can be clearly documented in nineteenth-century Fiji through Tongan incursion into Lau. The historian Derrick's (1950:121) vivid descriptions of canoe-building sojourner communities and the processes of settlement provide an analogy well worth considering:

In Tonga, there was little timber of a size and quality suitable for the construction of these large vessels, and it became the practice for parties of Tongans to sail up on the wind to Lakeba, arrange with the chiefs there for logs and food in exchange for Tongan bark cloth, weapons, or services in war, and then to establish themselves on islands such as Vulaga and Kabara and build, or help to build, the canoes....

The building of a large canoe took from three to five years, or even longer. Altogether, the trip to Fiji, the work of building the canoe, and the return journey commonly occupied up to seven years; and the temporary Tongan settlements became permanent as parties overlapped. [Emphasis added.]

Tongan immigration to Lau was substantial by the 1860 s and a Tongan chief, $\mathrm{Ma}$ 'afu, was recognized as the group's paramount head. If not for concerns by the King of Tonga over Ma'afu's growing power, and then annexation of Fiji by Great Britain in 1874, his control and Tongan hegemony might have been extended throughout the entirety of the archipelago (Derrick 1950:118-131). Even today this Tongan presence continues to be documented in Lau not only through linguistics but in highly visible material forms such as bark cloth manufacture and design, and in the use of Tongan ta 'ovala (waist mat) on formal occasion. In this light "a few extra squiggles on some clay pots in Fiji," to borrow from Best (2002:31), may indeed tell a story worth considering.

\section{ACKNOWLEDGMENTS}

The Sigatoka Sand Dunes 2000 archaeological program was undertaken in coordination with the Fiji Museum and National Trust for Fiji. Despite escalating turmoil as a result of a political coup, museum and trust personnel provided continuous support and assistance. Among the several individuals involved here, I am particularly grateful to Sepeti Matararaba and Jone Balenaivalu of the museum and Tui Komaimua, then of the trust. Fieldwork was conducted as one component of a field school in archaeological methods offered by Simon Fraser University. I am grateful to the 
students who were involved in this program as well as Professor Philip Hobler, SFU, who assisted with their supervision. Lori White, Jessi Witt, Alice Story, Andrew Barton, Margie Purser, and David Steadman are gratefully acknowledged for their assistance and insights into analysis, interpretation, and/or graphics production. I also thank the three reviewers for their insightful comments and critique of the paper. Funding for this project was provided by National Geographic Scientific, Exploration and Research Committee, Simon Fraser University International Programs, and an SSHRC Small Project Grant administered through Simon Fraser University.

\section{REFERENCES}

BEDFORD, STUART

2000 Pieces of the Vanuatu Puzzle: Archaeology of the North, South and Central. Ph.D. diss., Australian National University, Canberra.

Best, Simon B.

1984 Lakeba: The Prehistory of a Fijian Island. Ph.D. diss., University of Auckland, Auckland.

1987a A preliminary report on the Sigatoka Dune burials. Domodomo 3:2-15.

$1987 b$ Long distance obsidian travel and possible implications for the settlement of Fiji. Archaeology in Oceania 22:31-32.

1989 The Sigatoka Dune Burials. Unpublished report on file with the Fiji Museum, Suva.

2002 Lapita: A View from the East. New Zealand Archaeological Association Monograph 24, Auckland.

BIRKS, LAWRENCE

1973 Archaeological Excavations at Sigatoka Dune Site, Fiji. Bulletin No. 1. Suva: Fiji Museum.

Burke, Christine

1995 Archaeologist's Report. Fiji Museum Archaeology Newsletter. Suva: Fiji Museum.

Burley, DAVID V.

1997 Archaeological Research Sigatoka Dune National Park, June 1996. Unpublished report on file with Fiji Museum, Suva.

1998 Archaeology and the Tongan past: 2850-150 B.P. Journal of World Prehistory 12:337392.

2002 Archaeology of the Sigatoka Sand Dunes National Park: Report on the 2000 Field Season. Unpublished report on file with Fiji Museum, Suva.

2003 Dynamic landscapes and episodic occupations: Archaeological interpretation and implications in the prehistory of the Sigatoka Sand Dunes, in Pacific Archaeology: Assessments and Prospect: 327-335, ed. Christophe Sand. Le Cahiers de l'Archeologie en Nouvelle Calédonie 15. Noumea.

Burley, David V., and William R. Dickinson

2004 Late Lapita occupation and its ceramic assemblage at the Sigatoka Sand Dune site, Fiji, and their place in Oceanic prehistory. Archaeology in Oceania 39:12-23.

Burley, David V., and Robert Shortland

1999 Report on 1998 Field Work Activities, Sigatoka Dunes National Park, Viti Levu, Fiji. Unpublished report on file with Fiji Museum, Suva.

Clark, Geoffrey R.

1999 Post-Lapita Fiji: Cultural Transformation in the Mid-sequence. Ph.D. diss., Australian National University, Canberra.

Clark, Geoffrey R., and Tarisi Sorovi-Vunidilo

1997 Fijian double spouted vessels. Domodomo 11(2):6-14.

Crosby, Andrew

1988 Beqa: Archaeology, Structure and History in Fiji. M.A. thesis, University of Auckland, Auckland.

1991 Further Burials at the Sigatoka Sand Dunes (Site VL 16/1). Unpublished report on file with Fiji Museum, Suva.

De Biran, Antoine

2001 The Holocene Geomorphic Evolution of the Sigatoka Delta, Viti Levu, Fiji Islands. Ph.D. diss. University of the South Pacific, Suva. 
Derrick, R. A.

1950 A History of Fiji (Revised Edition). Suva: Government Press.

Di Piazza, Anne

1998 Efficiency of calcium-carbonate oven stones. Archaeology in Oceania 33:84-87.

Dickinson, William R.

1968 Sigatoka Sand Dunes, Viti Levu (Fiji). Sedimentary Geology 2:115-124.

Dickinson, William R., David V. Burley, Patrick D. Nunn, Atholl Anderson, Geoffrey

Hope, Atoine de Biran, Christine Burke, and Sepeti Matararaba

1998 Geomorphic and archaeological landscapes of the Sigatoka Sand Dune site, Viti Levu, Fiji. Asian Perspectives $37: 1-31$.

Dumont D’URville, J.S.C.

1831 Notice sur les îles du Grand Océan et sur l'origine des peuples qui les habitent. Bulletin de la Société de Géographie $17: 1-21$.

Frost, Everett L

1974 Archaeological Excavations of Fortified Sites on Taveuni, Fiji. Asian and Pacific Archaeology Series No. 6. Honolulu: University of Hawai'i.

1979 Fiji, in The Prehistory of Polynesia: 61-81, ed. Jessi Jennings. Cambridge, MA: Harvard University Press.

Galipaud, Jean C.

1996 New Caledonia, some recent archaeological perspectives, in Oceanic Culture History, Essays in Honour of Roger Green: 297-305, ed. Janet Davidson, Geoff Irwin, Foss Leach, Andrew Pawley, and Dorothy Brown. New Zealand Journal of Archaeology Special Publication. Dunedin.

Geraghty, PAUl

1983 The History of the Fijian Languages. Oceanic Linguistic Publication No. 19. Honolulu: University of Hawai'i Press.

GIFFORD, EDWARD W.

1951 Archaeological Excavations in Fiji. Anthropological Records 13(3). Berkeley: University of California Press.

Green, Roger C.

1963 A suggested revision of the Fijian sequence. Journal of the Polynesian Society 72:235253.

1974 A review of portable artifacts from Western Samoa, in Archaeology in Western Samoa, Vol. 2: 245-275, ed. Roger C. Green and Janet M. Davidson. Auckland Institute and Museum Bulletin 7. Auckland.

\section{Hudson, Elizabeth}

1994 Sigatoka Dune Site Archaeological Rescue Project 1993. Unpublished report on file with Fiji Museum, Suva.

Hunt, Terry L.

1980 Toward Fiji's Past; Archaeological Research on Southwestern Viti Levu. M.A. thesis, University of Auckland, Auckland.

1986 Conceptual and substantive issues in Fijian prehistory, in Island Societies: Archaeological Approaches to Evolution and Transformation: 20-32, ed. Patrick V. Kirch. Cambridge: Cambridge University Press.

1987 Patterns of human interaction and evolutionary divergence in the Fiji Islands. Journal of the Polynesian Society 96:299-334.

Hunt, Terry L., K. Aronson, E. Cochrane, J. S. Field, L. Humphrey, and T. Rieth

1999 A preliminary report on archaeological research in the Yasawa Islands. Domodomo $12(2): 6-43$.

KIRCH, PATRICK V.

1984 The Evolution of the Polynesian Chiefdoms. Cambridge: Cambridge University Press.

2000 On the Road of the Winds: An Archaeological History of the Pacific Islands before European Contact. Berkeley: University of California Press.

Kirch, Patrick V., and Roger C. Green

2001 Hawaiki, Ancestral Polynesia: An Essay in Historical Anthropology. Cambridge: Cambridge University Press. 
Marshall, Yvonne, Andrew Crosby, Sepeti Matararaba, and Shannon Wood

2000 Sigatoka: The Shifting Sands of Fijian Prehistory. University of Southampton, Department of Archaeology Monograph 1. Oxford: Oxbow Books.

Oliver, Douglas L.

1989 Oceania: The Native Cultures of Australia and the Pacific Islands. Honolulu: University of Hawai'i Press.

PARRY, JOHN

1987 The Sigatoka Valley: Pathways into Prehistory. Bulletin 9. Suva: Fiji Museum.

PAwley, ANDREW

1972 On the internal relationships of Eastern Oceanic languages, in Studies in Oceanic Culture History, Volume 3, ed. R. C. Green and M. Kelley. Honolulu: Bishop Museum Press.

Pawley, Andrew, and T. Sayaba

1971 Fijian dialect divisions: Eastern and Western Fijian. Journal of the Polynesian Society $80: 405-436$.

Pawley, Andrew, ANd Roger C. Green

1973 Dating the dispersal of the Oceanic languages. Oceanic Linguistics 12:1-67.

Petchey, Fiona

1995 The Archaeology of Kudon: Archaeological Analysis of Lapita Ceramics from Mulifanua and Sigatoka, Fiji. M.A. thesis, University of Auckland, Auckland.

Pietrusewsky, Michael, M. Douglas, and R. Ikehara-Quebral

1994 The Human Osteology of the Sigatoka Dune Burials (Site VL 16/1), Viti Levu, Fiji Islands. Unpublished report on file Department of Anthropology, University of Hawai'i, Honolulu.

Rechtman, Robert B.

1992 The Evolution of Sociopolitical Complexity in the Fiji Islands. Ph.D. diss., University of California, Los Angeles.

SAND, Christophe

1990 The ceramic chronology of Futuna and Alofi: An overview, in Lapita Design, Form and Composition: 123-133, ed. Matthew Spriggs. Occasional Papers in Prehistory No. 19. Canberra: Australian National University.

1995 "Le Temps d'Avant": La Prehistoire de la Novelle-Caldonie. Paris: l'Harmattan.

1996 Recent developments in the study of New Caledonia's prehistory. Archaeology in Oceania 31:45-70.

1998 Archaeological research on 'Uvea Island, Western Polynesia. New Zealand Journal of Archaeology 18:91-123.

Stuiver, M., P. J. Reimer, E. Bard, J. W. Beck, G. S. Burr, K. A. Hughen, B. Kromer, F. G. McCormac, J. Plicht, and M. Spurk

1998 INTCAL 98 Radiocarbon age calibration, 24,000-0 cal B.P. Radiocarbon 40:1041-1083.

Tonganivalu, Deve

1917 Fijian property and gear, in Transactions of the Fijian Society: 1-18, Suva.

VISSER, EDWARD

1994 The Prehistoric People from Sigatoka: An Analysis of Skeletal and Dental Traits as Evidence of Adaptation. Ph.D. diss., University of Otago, Dunedin.

WARD, Graeme K.

1979 Prehistoric Settlement and Economy in a Tropical Small Island Environment. The Banks Islands, Insular Melanesia. Ph.D. diss., Australian National University, Canberra.

Williams, Thomas

1858 Fiji and the Fijians, Vol. 1, ed. G. S. Rowe, London: Alexander Heyland.

\section{APPENDIX A}

The following radiocarbon dates are based on small charcoal samples collected from stratigraphic contexts associated with either the Fijian Plainware or Navatu phase components. Sample pretreatments, including combustion, were carried 
out in the Department of Archaeology at Simon Fraser University. Purified $\mathrm{CO}_{2}$ samples were then submitted for AMS measurement to the Center for Accelerator Mass Spectrometry (CAMS) at the Lawrence Livermore National Laboratory. A noncombusted portion of each sample was submitted to the IRMS Laboratory at the University of British Columbia for $\delta^{13} \mathrm{C}$ measurement. Calibrations were done using OxCal Version 3.9 using INTCAL98 (Stuiver et al. 1998). Radiocarbon dates were not reduced for southern hemispheric correction.

CAMS-70090 $1400 \pm 40, \delta^{13} \mathrm{C}=-28.3$, Navatu Phase. Unit $15 \mathrm{E}, 10 \mathrm{~cm}$ depth below surface $(\mathrm{dbs})$, Stratum I. Collected June 2000. Calibration 605-670 C.E. at $1 \sigma, 560-700$ C.E. at $2 \sigma$.

CAMS-70091 $1430 \pm 40, \delta^{13} \mathrm{C}=-27.2$, Navatu Phase. Unit 2E, 3-5 cm dbs,

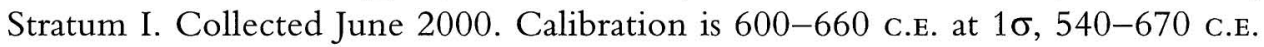
at $2 \sigma$.

CAMS-70920 $1480 \pm 40, \delta^{13} \mathrm{C}=-27.3$, Navatu Phase. Unit $15 \mathrm{~F}, 10 \mathrm{~cm}$ dbs,

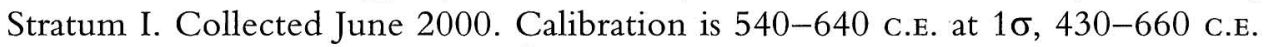
at $2 \sigma$.

CAMS-68192 $1540 \pm 40, \delta^{13} \mathrm{C}=-26.0$, Fijian Plainware Phase. Unit $14 \mathrm{~K}$, $25 \mathrm{~cm}$ dbs, earth oven feature. Collected June 2000. Calibration is 430-600 C.E. at $1 \sigma, 420-620$ C.E. at $2 \sigma$.

CAMS-68191 $1550 \pm 40, \delta^{13} \mathrm{C}=-27.4$, Fijian Plainware Phase. Unit 14E, $51 \mathrm{~cm} \mathrm{dbs,} \mathrm{Stratum} \mathrm{III/IV.} \mathrm{Collected} \mathrm{June} \mathrm{2000.} \mathrm{Calibration} \mathrm{is} 430-560$ C.E. at $1 \sigma, 420-610$ C.E. at $2 \sigma$.

CAMS-68194 $1620 \pm 40, \delta^{13} \mathrm{C}=-25.5$, Fijian Plainware Phase. Unit 14F, 44 $\mathrm{cm}$ dbs, Stratum III/IV. Collected June 2000. Calibration is 390-540 C.E. at $1 \sigma$, $340-540$ C.E. at $2 \sigma$.

CAMS-68195 $1310 \pm 40, \delta^{13} \mathrm{C}=-24.5 / \mathrm{CAMS} 709211410 \pm 40, \delta^{13} \mathrm{C}=$ -24.6 .

Combined age $1360 \pm 40$, Fijian Plainware Phase. Unit $16 \mathrm{G}, 40-45 \mathrm{~cm}$ dbs, Stratum III. Collected June 2000. Calibration is 650-685 C.E. at $1 \sigma, 610-770$ C.E. at $2 \sigma$.

\section{ABSTRACT}

Continued erosion of the Sigatoka Sand Dunes on the western coast of Viti Levu, Fiji has exposed discrete assemblages of ceramics associated with all phases of Fijian prehistory. Excavations here in 2000 investigated stratigraphically separated occupation floors associated with Fijian Plainware and Navatu phase components, respectively radiocarbon dated to between ca. $450-550$ C.E. and 550-650 C.E. The excavations and analysis of recovered data allow for a clarification of previous misunderstandings of the mid-sequence occupation at the site as well as its associated uses and features. These data further bear upon the Plainware/Navatu phase transition for Fiji as a whole. In the Lau Islands of southeastern Fiji this transition is described as abrupt and attributable to influences or a population movement from Vanuatu. Mid-sequence ceramic and other data from Sigatoka illustrate a similar break that potentially represents different cultural traditions. Keywords: Fiji, Sigatoka, excavation, ceramics, migration. 